\title{
Pinel e o nascimento do alienismo
}

\author{
Pinel and the birth of alienism
}

Pinel y el nacimiento del alienismo

\section{Manoel Olavo Loureiro Teixeira*}

Instituto de Psiquiatria da Universidade Federal do Rio de Janeiro - IPUB, Rio de Janeiro, Rio de Janeiro, Brasil

\begin{abstract}
RESUMO
O artigo discute a constituição do alienismo, na virada do século XVIII para o século XIX, como a primeira especialidade médica. Ele descreve as bases sobre as quais o alienismo organiza-se na Europa, de uma perspectiva histórica, empregando fontes primárias e secundárias. A biografia de Philippe Pinel, considerado o fundador da moderna psiquiatria, é apresentada, especialmente sua participação na reforma dos hospitais de Bicêtre e Salpêtrière, em Paris. Finalmente, o trabalho analisa a contribuição de Pinel no campo da clínica psiquiátrica, das causas e classificação da alienação mental e na criação do tratamento moral.

Palavras-chave: história da psiquiatria, alienismo, tratamento moral, Pinel.
\end{abstract}

\begin{abstract}
The article discusses the constitution of alienism in the turn of the eighteenth to the nineteenth century as the first medical specialty. It describes the basis upon which alienism was organized in Europe from a historical perspective, using primary and secondary sources. The biography of Philippe Pinel, considered the founder of modern psychiatry, is presented; especially his participation in the reform of Bicêtre and Salpêtrière hospitals in Paris. Finally, the work also analyzes Pinel's contributions in the field of psychiatric clinic, causes and classification of mental alienation and in the creation of moral treatment.
\end{abstract}

Keywords: history of psychiatry, alienism, moral treatment, Pinel.

\section{RESUMEN}

El artículo aborda la constitución del alienismo en la vuelta del siglo XVIII hacia el siglo XIX, como la primera especialidad médica. Él describe la base sobre la cual el alienismo se organiza en Europa, desde una perspectiva historica, con el uso de fuentes primarias y secundarias. La biografia de Philippe Pinel, considerado el fundador de la moderna psiquiatría, se presenta; con énfasis en su participación en la reforma de los hospitales de Bicêtre y Salpêtrière, en Paris. Por último, el artículo analiza la contribución de Pinel en el campo de la clínica psiquiátrica, las causas y la clasificación de la alienación mental, y la creación del tratamiento moral.

Palavras-claves: historia de la psiquiatria, alienismo, tratamiento moral, Pinel. 
A psiquiatria, como é conhecida hoje, nem sempre existiu. 0 entendimento moderno da psiquiatria - uma especialidade médica encarregada de tratar os transtornos mentais - é um fenômeno recente. Surgiu há pouco mais de duzentos anos. Seu marco de fundação foi o trabalho do médico francês Philippe Pinel (1745-1827) nos hospitais de Bicêtre e Salpêtrière, em Paris, e a publicação dos seus livros Nosografia Filosófica (1798) e Tratado Médico-Filosófico sobre a Alienação Mental, ou a Mania (1801). Este artigo discutirá o processo histórico de nascimento da psiquiatria, em sua matriz europeia, quando ela se consolidou como especialidade médica com o nome de alienismo; vale dizer, a que trata de alienados e da alienação mental. O termo psiquiatria (psychiaterie), criado pelo alemão Johan Christian Reil (1759-1813), só se popularizou no final do século XIX. Neste trabalho, usaremos o termo alienismo, por melhor corresponder à época abordada.

\section{O hospital geral e a grande internação}

Ao longo dos séculos XV e XVI, devido ao aumento da crise econômico-social e à crescente urbanização, multiplicou-se o número de miseráveis nas cidades europeias. Com a crise do feudalismo e as mudanças sociais, milhares de camponeses desempregados deslocaram-se para as grandes cidades, onde viviam nas ruas como mendigos. Diante disto, surgiu um novo discurso entre os membros das classes dirigentes, defendendo a reorganização das ações de caridade. Advogava-se o recolhimento dos pobres a instituições e sua diferenciação entre pobres válidos (isto é, os que podem trabalhar) e inválidos (Postel \& Quetel, 1994, p. 108-109). Com efeito, na França, na Espanha, na Holanda, na Alemanha, na Suíça e na Inglaterra, o internamento de pobres e mendigos começou a partir do século XVI. Boa parte deles era recolhida a hospitais gerais, instituições que desempenhavam um papel combinado de hospital médico, asilo, pensão, prisão, oficina de trabalho, orfanato e reformatório (Dowbiggin, 1991, p. 3). O hospital geral era uma instituição de caridade, mas exibia aspectos coercitivos inegáveis, como aprisionamento forçado e trabalho obrigatório para os pobres válidos. Ele tinha por função acolher indistintamente todos os errantes: mendigos, idosos, crianças, sarnentos, epilépticos, venéreos, loucos, enfermos em geral. Os mendigos inválidos tornavam-se moradores. Os mendigos válidos eram estimulados ao trabalho e ao sustento próprio. Os internos passavam os dias envolvidos em atividades de trabalho e práticas religiosas, como orações, leituras de textos cristãos e missas. Com o tempo, o internamento se tornou maciço e as mais variadas figuras da exclusão social foram recolhidas a 
hospitais gerais. Trata-se da experiência que Foucault (1989, p. 4578) chamou de "a grande internação".

Para Foucault (1989, p. 49), 1656 é a data chave para a compreensão deste processo na França. Nesse ano, um decreto real fundou o Hospital Geral de Paris, reunindo instituições já existentes, como o Grande e o Pequeno Pitié, Saint-Lazare, lês Petites Maisons, Bicêtre e Salpêtrière. Estes múltiplos locais de internação, alguns deles antigos leprosários, foram agrupados sob uma única administração e designados aos pobres de Paris. Ao mesmo tempo, o Hôtel-Dieu mantinha um funcionamento mais hospitalar, no sentido médico do termo, embora também recebesse miseráveis e loucos. A fundação do Hospital Geral, junto com a criação da intendência geral de polícia, foi uma tentativa do poder real de enfrentar a anarquia social que assolava Paris, tomada por uma multidão de 40.000 mendigos e vagabundos de todo tipo. De imediato, entre 4000 a 5000 mendigos foram internados. Poucos anos após sua inauguração, o hospital geral de Paris abrigava 6000 pessoas, cerca de $1 \%$ da população da cidade (Foucault, 1989, p. 55). Em 1662, um decreto real determinou a fundação de hospitais gerais em todas as grandes cidades da França. Além de pobres, a instituição recebia detenções políticas: suspeitos de subversão, de heresia ou de posições antimonárquicas eram aprisionados nas suas dependências. Dentre as vítimas deste recolhimento amplo e indiferenciado estavam os loucos, certamente uma minoria junto à extensa população internada. A estratégia de internação de excluídos sociais conjugou a ação punitiva e fiscalizadora do Estado a um ideal de caridade religiosa. Este ideário, até então exclusivo das casas de caridade pertencentes às ordens religiosas, passou a ser visto como uma responsabilidade do poder monárquico. Esta reunião de assistência e repressão não se limitou à França, mas atingiu toda a Europa. Surgiram as casas de misericórdia na Espanha, os hospitais gerais em Roma, Veneza e Turim, as Zuchthauser na Alemanha, as Doll-Huis em Amsterdam e as Workhouses na Inglaterra (Postel \& Quetel, 1994, p. 109-110).

\section{As lettres de cachet}

Antes da Revolução francesa, o poder judiciário e o poder monárquico compartilhavam a sequestração e o internamento de loucos nos hospitais gerais. Os procedimentos eram complexos e superpostos. Podiam ocorrer por ordem judicial de algum tribunal, ou por via de interdição, determinada pelo juiz (Castel, 1991, p. 23). Porém, a maioria das internações era feita por meio de uma lettre de cachet (carta régia), uma ordem simples, com o sinete pessoal do Rei, feita a pedido da família ou da autoridade pública. A lettre de cachet 
transmitia diretamente ao destinatário uma ordem de prisão, exílio ou confinamento sem julgamento. Assim, quando um louco perturbava a ordem pública, a chefia de polícia de Paris, ou os intendentes nas províncias, solicitavam uma lettre de cachet ao Rei, autorizando seu recolhimento a um hospital geral. Da mesma forma, quando um louco ameaçava a ordem familiar, a família solicitava seu internamento. Contudo, o papel do hospital geral foi questionado a partir da Revolução Francesa (1789). Ele passou a representar o absolutismo real, cujo poder discricionário estava sendo violentamente combatido. As lettres de cachet tornaram-se um símbolo dessas internações abusivas. Durante 0 período revolucionário, empreendeu-se uma reforma radical no funcionamento do hospital geral de Paris e a maior parte dos internos foi libertada. Em 16 e 26 de março de 1790, decretos da Assembleia Nacional determinaram a libertação de todos os aprisionados por lettres de cachet, e a emissão destas foi definitivamente abolida (Postel \& Quetel, 1994, p. 162). O ambiente revolucionário exigiu a reformulação do funcionamento dos hospitais gerais, por sua simbologia.

\section{Contexto histórico de surgimento do alienismo}

O alienismo surgiu na França, na virada do século XVIII para o século XIX, como a primeira especialidade médica, num campo até então dividido entre clínica geral e cirurgia. Nesse momento, articulou-se um consenso em torno de um discurso médico e de uma prática clínica destinada à loucura e o alienismo se constituiu como disciplina. O modelo assistencial desenvolvido por Philippe Pinel, em plena efervescência política da Revolução Francesa, tornou-se o paradigma do campo nascente. $O$ advento do alienismo associou-se às grandes transformações sociais do período, quando se verificou o fim das Monarquias Absolutistas e o surgimento das modernas sociedades liberais-burguesas. Foi o tempo das revoluções democráticas, cujos marcos foram a Revolução Francesa (1789) e a Revolução Americana (1776). "Liberdade, Igualdade e Fraternidade" era o lema triunfal da Revolução Francesa. Muitas destas características políticas, jurídicas e institucionais se expandiram posteriormente para outros países europeus, durante as Guerras Napoleônicas e as revoluções liberais da Primavera dos Povos (1848). O alienismo consolidou-se no contexto histórico da França pós-revolucionária e tornou-se uma especialidade médica especial, menos por questões teóricas internas, e mais pela natureza diferenciada do objeto com o qual precisava lidar. Ele nasceu com a incumbência de tratar da população de loucos já encerrada dentro dos hospitais gerais das cidades europeias, herança sem dono e rosto sem esperança da multidão de doentes, 
pobres, mendigos, órfãos, menores infratores, idosos, libertinos, hereges, prostitutas, venéreos, sarnentos, bêbados, pensionistas pagantes, nobres dissipadores, criminosos comuns, presos políticos, inimigos da monarquia, ali recolhidos durante o período que Foucault (1989, p. 45-78) denominou "a grande internação", nos séculos XVII e XVIII.

Em sua origem, o alienismo ligou-se inextrincavelmente ao ideário da modernidade. A crença no poder da ciência, geradora do progresso da civilização, dominava os meios científicos e culturais. O alienismo foi produto dos novos paradigmas do pensamento científico e filosófico, sobretudo daqueles relacionados ao iluminismo, ou filosofia das luzes. Ele surgiu como um aparato de vanguarda da intervenção médico-científica na vida do indivíduo e da sociedade, prometendo recuperar alienados mentais através da ação médica. Isto significou um tratamento possível para pessoas até então vistas como irrecuperáveis, por serem privadas do precioso atributo da razão, e cujo destino invariável seria a errância, o abandono em asilos ou o recebimento de caridade religiosa. Para Swain (1997, p. 63), de todas as transformações ocorridas nessa época, a mais significativa envolveu a mudança de mentalidade.

A evolução da ciência e a filosofia iluminista engendraram uma visão humanitária. Com o advento do alienismo, a ciência incorporou esta atitude em relação à figura do louco, numa espécie de extensão da ideia revolucionária dos direitos humanos. A curabilidade da loucura foi admitida e, mais do que isso, perseguida como objetivo. Antes, cabia à caridade cristã a tarefa de cuidar dos insanos, junto dos miseráveis, leprosos, órfãos etc. Agora, a ciência era a encarregada desta tarefa, numa perspectiva humanista, científica e laica. $\mathrm{Na}$ sociedade das luzes, a ciência queria mostrar-se mais eficiente do que a religião. Seu objetivo era recuperar os insanos para o terreno da razão, tornando-os aptos a participar do novo mundo que se descortinava: o mundo da revolução burguesa. Desenvolvida na Europa, a experiência alienista gradualmente alcançou outros países do mundo ocidental. Consolidou-se a ideia de uma internação exclusivamente destinada a tratar insanos - uma especialização técnica e institucional. A construção de manicômios para os alienados mentais, com a direção entregue a um novo tipo de médico, 0 alienista, tornou-se sinônimo de filantropia e avanço científico, sendo adotada por diversos países. O alienista reunia os méritos de cientista e de benfeitor humanitário.

\section{O louco e o projeto de cidadania do liberalismo}

No contexto de transformação social do século XVIII, uma ideia se impunha a cientistas, filósofos e juristas: a construção de um projeto 
de cidadania universal, próprio do liberalismo (Castel, 1991). Este projeto apareceu como crítica à sociedade hierarquizada e desigual do regime monárquico absolutista, dividida entre nobreza, clero e o restante da população. No antigo regime, as pessoas desempenhavam papéis sociais fixos e pré-definidos, de acordo com a vontade divina. Os direitos de um nobre eram superiores aos de um camponês. Raramente alguém se deslocava de um estrato social para outro. Porém, no mundo transformado da revolução burguesa, os indivíduos deviam ser iguais perante a lei, detentores de direitos e deveres e responsáveis por seus atos. Cada um deveria ser dono de seu destino. Grosso modo, esta concepção correlacionou-se ao desenvolvimento do modo de produção econômica capitalista e sua ideologia. Todos os cidadãos deveriam incorporar-se à ordem contratual que define o liberalismo e estimula a produção, o regime de trocas e a ascensão da burguesia. As leis se tornam universais e seu regime deve ser respeitado por cada um. A jurisprudência do liberalismo estabelece direitos e deveres para cada cidadão. Caso ele não os cumpra, comete um desvio passível de punição. Assim, os pobres, mendigos e excluídos, antes recolhidos em massa a grandes instituições caritativas, deveriam procurar seu caminho de trabalho e sobrevivência dentro da nova ordem social através do esforço pessoal, prescindindo da caridade religiosa. Cada indivíduo era livre para agir e empreender trocas econômicas e relações afetivas e sociais. Se não o fizesse, ou se optasse por desrespeitar a lei e a propriedade, responderia criminalmente. $\mathrm{Na}$ sociedade liberal, a pobreza não era mais vista como condenação ou punição divina: ela era uma escolha. Quem fosse pobre poderia deixar de ser, por meio do trabalho. Ao criminoso comum, consciente de sua ação transgressiva, caberia a punição judicial exercida pelo Estado.

Entretanto, o louco permaneceria como um enigma perante este projeto. Desviante, ele não se enquadra nesse modelo e continua sendo objeto de uma percepção contraditória. Inspirava, ao mesmo tempo, piedade e medo. Por um lado, entendia-se que o louco não era passível de punições convencionais, como a prisão, pela ausência de entendimento racional sobre a natureza desviante de seus atos. Por outro, o louco era visto como a imagem acabada da associabilidade, capaz de trazer riscos e transgredir leis, além de ser incapaz de participar do livre mercado de trocas afetivas e econômicas. O louco era uma anomalia. Foi necessário criar um estatuto de cidadania especial para sua figura. Segundo Castel:

Sobre o pano de fundo da sociedade contratual instaurada pela Revolução Francesa, o louco é uma nódoa. Insensato, ele não é sujeito de direito; irresponsável, não pode ser objeto de sanções; incapaz de trabalhar ou de servir, não entra no circuito regulado das trocas, essa livre circulação de 
mercadorias e de homens à qual a nova legalidade burguesa serve de matriz. Núcleo de desordem, ele deve, mais do que nunca, ser reprimido, porém, segundo um outro sistema de punições do que o ordenado pelos códigos para aqueles que voluntariamente transgrediram as leis. Ilha de irracionalidade, ele deve ser administrado, porém, segundo normas diferentes das que designam o lugar às pessoas normais e as sujeitam a tarefas em uma sociedade racional. (Castel, 1991, p. 19).

Portanto, o alienismo representou um marco da reformulação que o liberalismo exigiu em relação à figura do alienado mental no final do século XVIII. Cabe ao alienismo permitir a incorporação dos loucos, agora entendidos como alienados mentais, à nascente sociedade burguesa, desde que fossem tratados e recuperados. Caso isto não fosse possível, eles deveriam ser tutelado sob condições especiais. 0 objetivo seria proteger o alienado de si próprio e proteger a sociedade de seu perigo potencial. O manicômio tornou-se o local para observar, classificar, tratar, recuperar, isolar e reprimir estes indivíduos, em nome da ciência e da filantropia. O novo estatuto jurídico do alienado mental foi definido pela lei francesa de assistência aos alienados, aprovada em 30 de junho de 1838, que se tornou referência mundial na matéria (Castel, 1991; Postel \& Quetel, 1994). Assim, o caso dos alienados mentais foi o produto exemplar de uma nova concepção de indivíduo que se instalou. Conforme Castel (1991, p. 46):

"O indivíduo é sujeito autônomo enquanto for capaz de se dedicar a intercâmbios racionais. (...) O fundamento contratual do liberalismo impõe a aproximação entre o louco e a criança, a grande analogia pedagógica da medicina mental, no seio da qual toda sua história vai se desenvolver."

A nova concepção de abordagem da loucura veio se contrapor ao poder discricionário e hierarquizado da monarquia e da religião, esta última entendida como aliada da primeira. O ideário revolucionário do período continha um marcante componente ideológico anticlerical. Para o pensamento iluminista e liberal, caberia agora à ciência cumprir a tarefa antes executada pela religião. A Igreja Católica era uma inimiga a ser combatida. Seu interesse caridoso para com os loucos devia ser enfrentado. Doravante, a interpretação espiritual e metafísica da loucura, como fruto de punição divina, possessão demoníaca ou punição dos pecados, seria vista como uma forma de obscurantismo religioso. Tudo o que remetia aos valores católicos era repudiado como um instrumento a serviço do Antigo Regime Monárquico. Logo, não surpreende que foi justamente neste contexto que a ciência europeia tomou para si a tarefa de forjar uma 
alternativa laica de atenção e tratamento aos loucos, pensados como alienados mentais.

\section{Philippe Pinel: Uma pequena biografia}

Um consenso entre autores aponta Philippe Pinel como o introdutor do enfoque moderno na abordagem da alienação mental, especialmente pela publicação da "Nosografia Filosófica, ou o Método de Análise Aplicado à Medicina" (1798) e do "Tratado MédicoFilosófico sobre a Alienação Mental, ou a Mania" (1801). Em 1791, um comitê revolucionário nomeou Pinel como médico-chefe de Bicêtre, unidade do hospital geral de Paris, com a missão de reformular seu funcionamento (Postel \& Quetel, 1994). Em 1795, Pinel assumiu a direção da Salpêtrière. $O$ trabalho por ele desenvolvido junto aos loucos internados nas duas maiores unidades do hospital geral de Paris inaugurou o campo do alienismo, em plena efervescência da Revolução Francesa.

Philippe Pinel nasceu em 20 de abril de 1745 e morreu em 26 de outubro de 1826 (Pinel, 2007, p. 18). Inicialmente dedicou-se ao estudo de teologia e matemática. Depois estudou medicina em Toulouse e Montpellier, graduando-se em 1773. Em 1778, fixou-se em Paris. Atuou como médico, tradutor, editor e preceptor de filhos de famílias abastadas. Desiludido com a medicina oficial de Paris, trabalhou como jornalista de temas médicos. Em 1784, foi editor da Gazette de Santé. Posteriormente, foi médico de um dos mais conhecidos sanatórios privados de Paris, a Maison Belhomme de Santé, que admitia alienados mentais. Ali permaneceu nos cinco anos que antecederam a Revolução, reunindo observações sobre a alienação mental e formulando visões sobre sua natureza e tratamento (Goldstein, 1987, p. 67-72). Pinel foi um militante revolucionário de primeira hora. Era bem relacionado com os membros da Sociedade Real de Medicina e amigo pessoal do médico e filósofo Pierre Jean Georges Cabanis (1757-1808), cuja proteção Ihe permitiu tornar-se membro do círculo de intelectuais conhecidos como os Ideólogos. "Nos tempos conturbados que se seguiram à Revolução Francesa, uma comissão foi criada para administrar os hospitais de Paris. Cabanis era um dos seus membros. Uma visita da comissão à Bicêtre, onde havia grande número de alienados, recomendou a construção de dois hospitais dedicados exclusivamente aos insanos, que até então só recebiam tratamento no Hôtel-Dieu" (Goldstein, 1987, p. 70).

A esta altura, o hospital de Bicêtre funcionava de forma inteiramente não-medicalizada. A unidade, composta por sete pavilhões, recebia apenas homens, em boa parte loucos considerados incuráveis. Era dirigida por um "governador" que, após a revolução, passou a ser 
chamado de "vigilante". Atendentes leigos cuidavam da limpeza, da distribuição de comida e da segurança. Um pavilhão inteiro era reservado aos loucos, onde muitos viviam acorrentados, em celas imundas, sem qualquer tipo de tratamento. Entre as medidas tomadas pela nova comissão dos hospitais estava a nomeação de Pinel como médico-chefe de Bicêtre. Para este fato, pesaram seu comprometimento com a Revolução, sua experiência em Belhomme e sua amizade com Cabanis.

Pinel reorganizou o espaço institucional de Bicêtre e aplicou suas ideias acerca da abordagem dos alienados e do tratamento moral. Além disso, implantou medidas de cunho humanitário. No transcorrer deste processo, o manicômio surgiu do hospital geral reformado. Durante o período do Terror (1792-1794), do qual discordou politicamente, Pinel se afastou da Revolução. Ficou sob suspeição e chegou a ser acusado de esconder nobres foragidos em Bicêtre, como se fossem alienados. Por esta razão, recebeu a visita de uma comissão de inspeção liderada por Couthon, membro do Comitê de Salvação Pública. Nada ficou comprovado e o trabalho prosseguiu, Pinel permanecendo em Bicêtre até 1795. Então, novamente prestigiado, foi nomeado médico-chefe da Salpêtrière, a contrapartida feminina de Bicêtre. Lá, repetiu a experiência, firmando-se de vez como fundador do alienismo francês (Goldstein, 1987, p. 71). Em 1794, assumiu a cadeira de higiene na nova escola de medicina de Paris.

Os acontecimentos de Bicêtre e Salpêtrière tornaram-se emblemáticos para a constituição do alienismo. Em 1803, Pinel foi admitido no Institut de France e fez parte da primeira leva de agraciados com a Legion d'Honneur, criada por Napoleão (Serpa Jr., 1997, p. 24), mantendo a função de diretor de Salpêtrière até as proximidades de sua morte, em 1826, em consequência de um acidente vascular encefálico.

\section{Pinel e o mito de Bicêtre}

$\mathrm{Na}$ interpretação de Swain (1997, p. 165), a notoriedade obtida por Pinel deveu-se ao fato dele ter levado a ideia dos direitos do homem para dentro das celas infectas de Bicêtre e Salpêtrière. Sua atuação foi um momento marcante de um amplo movimento de reformas das atitudes e instituições que caracterizou o período. Aos poucos, o intento de tratar os alienados tornou-se de aceitação geral, e Pinel encarnou o novo ideal humanitário que surgia. Assim, o mito pineliano pode se constituir graças à "condensação de terapêutica e filantropia" (Swain, 1997, p. 174-175), cuja expressão habitual é traduzida por seu gesto de libertar os alienados das correntes em que ficavam presos. Este gesto está registrado nos quadros de Ch. Muller, 
para os alienados de Bicêtre, e de Tony-Robert Fleury, para as alienadas de Salpêtrière. Além de desacorrentar os insanos, Pinel teria enfrentado Couthon, membro do Comitê de Salvação Pública, em pleno Terror, durante visita de inspeção que pretendia interromper as reformas de Bicêtre. Pinel defendeu perante ele a necessidade de se criar novos meios de tratamento para os insanos: "tenho a convicção de que estes alienados só são intratáveis porque os privamos de ar e liberdade". Então Couthon, assustado com o que via, teria respondido: "Faça o que quiser. Eu os abandono a você. Mas temo que você seja vítima da própria pretensão" (Serpa Jr, 1997, p. 17-18). A humanidade do gesto pineliano tornou-se a imagem fundante da própria psiquiatria. Sua realidade histórica, porém, é questionável. Parece ter sido construída tardiamente por seu filho, Scipion Pinel, para resgatar o prestígio perdido pelo pai. Scipion constituiu, em 1823, a primeira narrativa completa do mito da libertação das correntes, no momento em que seu pai, doente, perdia prestígio frente a Esquirol. Scipion publica dois artigos: Sur L'Abolition des Chaînes des Alienés e Bicêtre em 1792: De L'Abolition des Chaînes (Postel \& Quetel, 1994, p. 152-161). O próprio Pinel, em seus escritos, não reivindicou para si o mérito da libertação dos loucos das correntes, mas o credita ao auxiliar JeanBaptiste Pussin, vigilante do pavilhão de Bicêtre. Quando Pinel chegou a Bicêtre, em 1791, Pussin já estava lá há quase uma década. Pouco se encontra sobre a libertação dos loucos das correntes no Tratado Médico-Filosófico. Na primeira edição (1801), Pinel se refere ao tema apenas numa nota de rodapé:

Foi-me fácil julgar, por comparação, a vantagem de evitar a reclusão muito rígida aos insanos; enquanto os mais extravagantes e os mais furiosos do Hospício de Bicêtre eram presos por correntes em suas celas, estavam em contínua agitação dia e noite: nada havia além de vociferações, algazarra e tumulto; mas desde que se estabeleceu o uso do colete ou camisola de força e a liberdade de errarem pelos corredores, sua efervescência evaporou-se em esforços contínuos durante o dia, quando se agitavam e atormentavamse sem perigo, dispondo-os à noite a um estado mais calmo e tranquilo. (Pinel, 2007, p. 197)

Na segunda edição do Tratado (1809), Pinel acrescentou:

quarenta infelizes alienados que gemiam sob o peso dos ferros após uma sucessão mais ou menos longa de anos foram postos em liberdade, apesar de todos os temores manifestados pelo bureau central, e permitimos que eles caminhassem livremente pelos pátios, contendo apenas os movimentos de seus braços 
por camisas de força.(citado por Postel \& Quetel, 1994, p. 154).

Depreende-se que não houve uma libertação indiscriminada dos alienados, mas sim a substituição das correntes pela camisa de força, permitindo a circulação durante o dia. Uma versão bem menos épica do que a divulgada pelo mito construído posteriormente.

\section{Pinel e a clínica psiquiátrica}

Para Bercherie (1989, p. 31-34), Pinel fundou a tradição da clínica psiquiátrica, permitindo sua constituição enquanto campo de observação e análise dos fenômenos perceptíveis da doença mental. Pinel criou uma atividade clínica específica, dentro da qual a loucura foi ordenada como objeto de intervenção médica por meio de uma prática a ela destinada. Graças a este procedimento, uma série de operações tornou-se disponível: (1) uma semiologia psiquiátrica, a partir do olhar do alienista que observa, convive e descreve o comportamento dos doentes; (2) uma classificação; (3) uma abordagem clínica, partindo dos sintomas para chegar até os quadros clínicos; (4) uma terapêutica específica, voltada para o tratamento concomitante das causas físicas e das causas morais da loucura, isto é, das paixões descontroladas, excessivas ou desviadas que estariam na base da insanidade (Beauchesne, 1989, p. 23-28).

Como dito, Pinel estava ligado ao grupo dos Ideólogos, que representou na França as correntes de pensamento inovadoras do século XVIII. Partilhava com eles a busca por princípios metodológicos de uma orientação verdadeiramente científica. Para os Ideólogos, a ciência deve ser uma atividade classificatória, baseada na observação empírica dos fenômenos. Segundo Oda \& Dalgalarrondo, desenvolveu-se um tipo de análise "baseada, sobretudo, em cuidadosa observação dos fenômenos, algo próximo do que, posteriormente, viria a ser chamado de análise psicológica" (Oda \& Dalgalarrondo como citado em Pinel, 2007, p. 21-22). Uma disciplina serve de modelo para esta orientação: a história natural, com seu espírito de descrição acurada, nomeação e ordenação dos fenômenos. Para Pinel:

Os princípios que devem orientar o médico na busca da verdade são os mesmos das outras ciências naturais; as mesmas regras para adquirir um gosto puro e conhecimento sólidos; a mesma atenção em tirar proveito dos preceitos gerais fornecidos pelos filósofos, a fim de assegurar a marcha e os progressos do espírito humano (Beauchesne, 1989, p. 24). 
A fim de atingir este objetivo, Pinel recomendava uma metodologia aos alienistas: Cumpre, em primeiro lugar, entregar-se a pesquisas nos hospitais e começar pelos sintomas vistos de maneira isolada e independente de toda classificação; 2) quando se tiver também feito um estudo particular dos sintomas durante algum tempo, passar-se-á ao seu conjunto, ou seja, ao andamento das doenças começando pelas agudas, por exemplo, tendo-se o cuidado de estudar a influência particular que os lugares, um regime, as afecções morais podem exercer sobre a doença; 3 ) somente depois de se ter adquirido familiaridade com as doenças simples ou limitadas a uma única ordem de sintomas, deve-se passar ao exame das que são mais complicadas $(. .$.$) ; 4) a necessidade de$ estabelecer uma ligação estreita em seus conhecimentos médicos e de formar uma experiência esclarecida exige, imperiosamente, que se classifiquem as doenças estudadas e que se as enquadrem nos diversos gêneros de uma distribuição simples e metódica. (Pinel, como citado em Beauchesne, 1989, p. 24).

Pinel defendia uma abordagem clínica que partisse dos sintomas para chegar aos quadros clínicos. O importante era permanecer nos limites da descrição empírica dos sintomas das doenças mentais, como um pesquisador das ciências naturais, para depois traçar os caminhos de uma classificação e de um tratamento, frutos da avaliação metódica obtida. O alienista deveria se ocupar exclusivamente daquilo que fosse captado pelos sentidos: os gestos, o comportamento, as expressões faciais, os movimentos, as emoções expressas pelos alienados. Já que a natureza profunda das lesões responsáveis pela alienação mental era desconhecida, o médico limitaria-se a descrever e classificar estas manifestações objetivas, evitando especulações. Segundo Pinel:

(...) o estudo dos ideólogos franceses e ingleses foi-me, portanto, necessário para partir de um termo fixo e para exprimir o caráter distinto das diversas espécies de alienados, descartando a propósito todo tema controverso, toda discussão metafísica: a marcha seguida em todas as partes da história natural serviu-me como guia, agarrei-me aos sinais exteriores, às mudanças físicas que poderiam corresponder às lesões das funções intelectuais e afetivas: assim é que foram descritos os traços da fisionomia, os gestos, os movimentos, que são como presságios da próxima explosão de um acesso de mania; a expressão da fisionomia, que caracteriza o acesso em seu auge ou declínio, não foi omitida bem como as diversas formas de crânio relacionadas às lesões dos sentidos internos, e que se 
tornaram objeto especial de minhas pesquisas (Pinel, 2007, p. 68).

Em sua definição, a loucura seria uma alteração das funções superiores do sistema nervoso. A alienação mental expressaria um tipo de desarranjo das funções intelectuais. Pinel reprovava as longas discussões abstratas da medicina sobre a verdadeira sede da lesão do entendimento, responsável pela loucura, considerando-as metafísicas e sem base na realidade. Para ele, bastava a descrição apurada dos sintomas de cada doença e sua ordenação num sistema simples e bem ordenado.

\section{O Tratado médico-filosófico sobre a alienação mental}

A primeira edição do "Tratado Médico-Filosófico sobre a Alienação Mental, ou a Mania" foi publicada em 1801. Uma segunda edição, bastante modificada, veio à luz em 1809 (Goldstein, 1987, p. 65). No livro, Pinel expõe suas ideias sobre sintomas, características, classificação, causas, abordagem e tratamento da alienação mental. A obra se tornou a principal referência do campo do alienismo durante o século XIX. O Tratado reuniu medicina e filosofia de um só golpe. Seu título ("Tratado Médico-Filosófico sobre a Alienação Mental") não deixa dúvidas a respeito. Para Pinel, a medicina encarregava-se do corpo e a filosofia encarregava-se da alma. Isto estabeleceu um novo território discursivo, com a retomada da antiga noção de doença da alma, na tentativa de lidar com as características da alienação mental. Graças a este procedimento, Pinel anexou à medicina o domínio das paixões humanas, retirando-o da órbita exclusiva do discurso religioso ou metafísico.

A publicação do Tratado Médico-Filosófico teve grande repercussão não só entre médicos, mas entre filósofos como Hegel, ou escritores como Stendhal (Postel \& Quetel, 1994, p. 152). Através da abordagem clínica e da descrição de uma terapêutica, a obra oferecia um novo olhar sobre a loucura. O louco não era somente um insensato, privado de razão. Existia uma comunicação possível, porque a razão nunca seria totalmente perdida. Haveria um resto de razão no alienado com o qual o alienista pode e deve dialogar. 0 filósofo alemão Hegel (1770-1831) escreveu que Pinel foi responsável por duas importantes contribuições: ter descoberto o resto de razão presente nos alienados e maníacos; e ter entendido que recuperar esta razão oculta era o próprio princípio da cura dos alienados (Postel \& Quetel, 1994, p. 152). 


\section{Classificação das formas de loucura}

Segundo Pinel, a classificação das formas de alienação devia se basear na descrição dos sintomas: "O princípio fundamental é o estudo preliminar e cuidadoso das diferentes lesões do intelecto e da vontade, manifestadas exteriormente como alterações do comportamento, nos gestos, no modo de falar e através de precisos distúrbios físicos" (Pessotti, 1996, p. 57).

Pinel criticava as classificações incompletas e assistemáticas de William Cullen e Boisoir de Sauvages e defendia o uso de critérios sintomatológicos: era preciso identificar sintomas que apontassem a presença dos danos, desvios ou debilitações do entendimento ou autocontrole, característicos da alienação mental. Graças a este critério, Pinel criou uma classificação que foi hegemônica durante a primeira metade do século XIX (Pessotti, 1996, p. 58): as quatro grandes espécies de alienação mental seriam: a mania, a melancolia, a demência e o idiotismo.

\section{As paixões e as causas morais da alienação mental}

No Tratado Médico-Filosófico, as paixões assumem o papel de principal causa da alienação mental: são as famosas causas morais da loucura. O destaque atribuído a elas tornou-se característico da psicopatologia pineliana. De acordo com Bercherie, as causas morais da alienação, segundo Pinel, podiam ser classificadas em dois grupos: 1) as paixões intensas, muito contrariadas ou prolongadas; e 2) os excessos de todos os tipos, as irregularidades dos hábitos de vida e a educação perniciosa, seja por brandura ou por dureza excessiva (Bercherie, 1989, p. 39). Na segunda edição do Tratado, Pinel definiu as paixões de forma ambígua, como um tipo desconhecido de alteração da sensibilidade físico-moral do indivíduo, no qual ambos os aspectos se influenciariam mutuamente:

De modo geral, as paixões são modificações desconhecidas da sensibilidade física e moral, das quais nós podemos somente discernir e notificar seus caracteres distintivos por intermédio de sinais exteriores. Qualquer oposição que possa aparecer entre elas, como a cólera, o pavor, a dor mais vívida, uma alegria repentina, é marcada, sobretudo, por espasmos variados dos músculos da face, que se mostram ao exterior por meio de traços salientes, traços estes que os poetas, os escultores e os pintores de primeira linha tem feito o estudo mais aprofundado. (Pinel, 1809, p. 25-26). 
Sob a rubrica das paixões, Pinel incluiu uma ampla gama de sentimentos, apetites e atitudes diante da vida: a alegria, o orgulho, o amor, o arrebatamento, a fome, o prazer, a dor, a volúpia, a tristeza, o desgosto, o medo, a cólera, a ira, o ciúme, o remorso, a culpa, a inveja, a irritação, a avareza, a vaidade, o sofrimento, o desejo de prestígio, a infelicidade amorosa, o fanatismo, a exaltação religiosa. Em sua concepção, as paixões agregam aspectos físicos e morais, existindo uma correlação dinâmica entre ambos. O alienista deve analisar os efeitos das paixões sobre a "economia animal" do corpo humano, isto é, sobre a fisiologia. De acordo com Pessotti, esta definição aponta para uma visão da loucura que poderia ser chamada de "psicobiológica", sustentada pelo conceito de sensibilidade moral. (Pessotti, 1996, p. 96).

No Tratado, Pinel cita o inglês Thomas Crichton, que catalogou diversos efeitos de paixões como a alegria, a cólera, o medo e a tristeza, no estado das vísceras e das grandes funções orgânicas, como a circulação e a respiração. Cada paixão teria um caminho natural de expressão no indivíduo. Porém, paixões represadas, excessivas ou desviadas do seu curso podiam levar à perda da razão. A entrega aos vícios, a dissipação dos costumes e a educação viciosa provocariam igual resultado. $O$ efeito das paixões seria particularmente prejudicial nos indivíduos predispostos, como os de temperamento melancólico. Pinel admitia que a obstrução extrema ou contínua de uma paixão podia desencadear a alienação mental em alguém dotado de extrema sensibilidade moral. (Pinel, 2007, p. 5455).

Desta forma, o alienismo pineliano assumiu um caráter essencialmente reeducativo. Seu objetivo seria corrigir desvios passionais, supostamente responsáveis pela insanidade, pelo uso de medidas de cunho moralizante. Pessotti afirma que a abordagem pineliana tem, na verdade, uma

intenção libertadora, coerente com a filosofia humanista do iluminismo. Os vícios, a degradação dos costumes, o entregarse acriticamente aos apetites parecem, ao alienista, limitações, barreiras que impedem o homem de atingir a plenitude de sua condição humana, a direção inteligente de sua própria vida. (...) Mesmo porque, na medida em que os maus costumes constituem um destempero passional, são capazes de lesar as funções mentais (Pessotti, 1996, p. 100).

\section{O papel do manicômio e do alienista}

Pinel condicionava o tratamento moral dos alienados ao ambiente no qual ele se realizava. Por este motivo, promoveu uma reestruturação 
no espaço institucional que, antes, abrigava a indistinção do hospital geral. O manicômio definiu uma nascente especialização institucional. Castel afirma que o "verdadeiro ato fundador de Pinel não é retirar as correntes dos alienados, mas sim o reordenamento do espaço hospitalar" (Castel, 1991, p. 83). Na concepção pineliana, os alienados poderiam ser reconduzidos à razão com o auxílio da própria instituição de tratamento. O ambiente em que vivia o alienado desempenhava um papel fundamental na sua recuperação (Bercherie, 1989, p. 41). O manicômio poderia afastá-lo das percepções habituais e da confusão da vida cotidiana, geradoras da doença, submetendo-o a uma disciplina severa e paternal, num mundo inteiramente regido pela lei médica. O manicômio, por si só, era um instrumento de cura. Logo, o seu espaço físico não era algo indiferente: a arquitetura e o funcionamento constituíam elementos decisivos do tratamento. As condições de salubridade, limpeza, ordem, organização e vigilância mereciam destaque. Atividades de trabalho e distração deviam ser levadas a cabo pelos alienados, num planejamento minucioso que considerasse as disposições de cada caso. O manicômio constituiria um tipo de sociedade humana especial, onde princípios de organização racional permitiriam a recuperação de indivíduos afetados pela educação, pela vida familiar e social.

Em última análise, estamos diante de um projeto de reeducação social, onde a arquitetura asseverava a pedagogia moral da loucura. No interior do manicômio, só devia permanecer quem fosse diagnosticado como doente mental. As demais figuras da exclusão social foram retiradas de cena. Os princípios classificatórios do alienismo foram aplicados na divisão e ocupação das alas do manicômio. A ideia fundamental quanto à arquitetura manicomial era a separação das diferentes classes de alienados (Postel \& Quetel, 1994 , p. 194), ou seja, sua distribuição pelo edifício deveria ser ditada pelas características dos sintomas e por sua classificação nosográfica. $O$ isolamento dos furiosos, por exemplo, impediria a propagação da perigosa atmosfera de contágio entre os alienados mais calmos. A disposição de andares, celas, janelas, pátios e corredores era discutida exaustivamente, tendo em conta os seus efeitos no tratamento dos doentes.

A criação de uma atmosfera de liberdade era propugnada, embora se mantivesse o uso de medidas repressivas, como o isolamento e o uso de camisas de força. Entretanto, medidas restritivas e punitivas deviam ser condicionadas ao plano de tratamento orientado pelo alienista. Nada seria aleatório. Era aceitável o uso de punição e intimidação, se estivesse de acordo com os propósitos do tratamento. Mas a violência gratuita e degradante não era admitida. $O$ alienista era a principal figura de referência do manicômio, encarnando um papel, ao mesmo tempo, acolhedor, repressivo e inspirador de 
virtudes morais. Ao fim e ao cabo, Pinel construiu a apoteose da figura do alienista. Ele desempenhava o papel central no recémcriado modelo institucional. Todas as decisões giravam ao seu redor. Profundo conhecedor de sua matéria, da natureza da doença e de cada doente em particular, o alienista seria responsável por qualquer decisão que envolvesse o ambiente manicomial. Ele devia representar um modelo para os alienados, aliando sabedoria, bondade e autoridade. Para Bercherie (1989, p.42): "O objetivo era subjugar e domar o alienado, colocando-o na estreita dependência de um homem que, por suas qualidades físicas e morais, seja adequado para exercer sobre ele uma influência irresistível e para modificar a cadeia viciosa de suas ideias".

\section{O tratamento moral}

A admissão de que a alienação mental era resultado de um distúrbio da sensibilidade físico-moral permitiu aliar o tratamento médico convencional a medidas de base moral, reunidas num projeto de base científica. Dessa maneira, Pinel integrou procedimentos como o uso da sangria, evacuantes, espasmódicos e banhos quentes e frios, de ordem física, a medidas ocupacionais, disciplinares, de consolo e de persuasão, de ordem moral. Assim se organizou um modelo de tratamento para fazer frente às alterações provocadas pelas paixões desvirtuadas: o tratamento moral.

Embora empregasse meios físicos, Pinel considerava as causas morais como as mais importantes. O tratamento proposto privilegiava justamente o manejo dessas causas. Aliás, a novidade do projeto pineliano foi o reconhecimento, feito por um discurso médico, da possibilidade de se tratar a alienação mental através dos meios morais. Segundo Swain: "O tratamento moral, conforme, pelo menos, era entendido por Pinel e Esquirol, é simplesmente um tratamento que, declarando secundários ou ineficazes os meios físicos de intervenção sobre o alienado, privilegia, pelo contrário, o apelo às faculdades intelectuais e aos sentimentos ou paixões" (Swain, 1994, p. 90).

Goldstein (1987, p. 80-89), por sua vez, destaca quatro princípios básicos do tratamento moral: (1) a doçura, isto é, o uso de palavras gentis e de atitudes de consolo a fim de conquistar a confiança dos alienados; (2) a autoridade, isto é, a imposição de uma atitude de respeito por meio da autoridade e de ações repressivas, caso necessário; (3) o combate incessante à ideia delirante; (4) o manejo das paixões como forma de combater ideias patológicas, isto é, as paixões patológicas devem ser contrabalançadas por outras, de natureza contrária, despertadas pelo próprio tratamento. 
Um plano de tratamento devia ser traçado para cada caso, a partir do estudo apurado de suas características. O alienista deveria considerar as particularidades e os interesses de cada doente. O objetivo era despertar reações no alienado, fazendo com que ele fosse abalado por choques emocionais e defrontado com seu próprio comportamento patológico. Goldstein (1987, p. 85) afirma que a teatralidade era um instrumento importante do tratamento moral. Dentre as medidas empregadas, observava-se com frequência uma espécie de teatro terapêutico, onde ocorria a encenação de julgamentos fictícios, nos quais o doente era julgado e absolvido de suas culpas imaginárias por juízes e advogados interpretados por membros da equipe; ou recebia visitas ameaçadoras de membros da equipe vestidos de modo assustador, para despertar medo; ou se promovia um encontro previamente planejado pelo alienista com uma pessoa significativa na vida do doente; ou se firmava um contrato jurídico com o alienado, onde ele se comprometia por escrito a mudar de atitude. Tudo isto era feito a fim de gerar impactos emocionais que, presumivelmente, iriam retirar o alienado do delírio.

Era tarefa do alienista visitar o doente com regularidade; conquistar sua confiança; estabelecer um canal de diálogo com ele; oferecer-Ihe consolo moral por meio de uma paciente argumentação persuasiva; alternar atitudes de brandura e de firmeza inabalável; confrontar o doente com suas contradições; repreendê-lo por suas atitudes errônea se resgatá-lo para o terreno da razão.

De modo especular, o tratamento moral deveria promover no doente o confronto com sua própria loucura. O objetivo final era despertar nele a consciência do absurdo e da inutilidade de suas crenças delirantes. Estes diferentes elementos, aliados a um regime de ordem, disciplina e trabalho, a regras rígidas de vida, ao ar puro, a exercícios físicos, à aplicação de medidas punitivas com fins pedagógicos, compunham o cenário de um tratamento inovador. $\mathrm{Na}$ sua base, destacava-se o intento de despertar o resto de razão oculto na mente dos alienados, pela atuação constante do alienista. No novo cenário, o principal papel pertence ao médico alienista.

\section{Considerações finais}

Ao longo dos séculos XVIII e XIX, houve um crescente interesse pelo tema da loucura na Europa. Médicos e pensadores denunciavam a crueldade dirigida aos loucos, muitos deles isolados, abandonados e acorrentados em alas infectas dos hospitais gerais. O ideário iluminista defendia uma nova abordagem capaz de recuperar os loucos para o campo da razão através da intervenção da ciência médica. A mudança de mentalidade cultural no período fez este projeto parecer possível e, mais do que isso, desejável. 
Dessa maneira, estabeleceu-se um novo olhar em relação ao alienado mental, caracterizado pela tríade: (1) humanização da abordagem; (2) busca de tratamento específico; (3) projeto de recuperação para a vida social. Por toda parte, foram promovidas experiências humanitárias, definindo formas inovadoras de abordagem da loucura. Deste conjunto de experiências e, em particular, do trabalho desenvolvido por Philippe Pinel nos hospitais de Bicêtre e Salpêtrière, em Paris, constituiu-se o alienismo, um novo ramo da medicina encarregado da alienação mental. Estes elementos só se consolidam em um determinado momento histórico, no contexto da Revolução Francesa. Coube ao alienismo o encargo de tratar dos loucos já internados nos hospitais gerais, herdeiros da multidão de excluídos sociais ali recolhidos durante o período que Foucault chamou de "a grande internação" (Foucault, 1989, p. 45-78).

Mais do que um avanço científico, o alienismo foi um projeto exemplar da reformulação que o nascente liberalismo exigia em relação à figura do doente mental no final do século XVIII. O nascimento do alienismo e de seu corolário institucional, o manicômio, assinalou o ponto em que a medicina assumiu a tarefa de tratar cientificamente de um problema antes relegado ao abandono ou ao cuidado religioso. Constituiu-se em um modelo assistencial para tratar indivíduos inadequados ao contrato social do liberalismo, visando sua recuperação para este projeto. Quando isto não fosse possível, os alienistas assumiriam a tutela destes indivíduos.

O modelo indistinto de reclusão do antigo hospital geral foi substituído por outro, exclusivamente voltado para a guarda e tratamento de comportamentos desviantes dos alienados mentais. Neste processo, o hospital geral remodelado transformou-se no moderno manicômio. Chegou-se ao acordo que marcaria a Europa, principalmente na segunda metade do século XIX: o manicômio era um instrumento de cura por excelência e a internação dos alienados mentais era uma medida médica e humanitária inquestionável. Tamanha crença na eficácia da internação manicomial nunca mais se repetirá. Por este motivo, Castel chamou a experiência europeia do século XIX de "a idade de ouro do alienismo".

Phillipe Pinel encarnou a imagem de fundador da moderna psiquiatria, a partir dos acontecimentos de Bicêtre e Salpêtrière. Como resultado de sua contribuição, uma série de operações tornou-se disponível: (1) uma semiologia psiquiátrica, criada pelo olhar do alienista que convivia, observava e descrevia o comportamento dos doentes; (2) uma classificação das formas de alienação; (3) uma abordagem clínica, partindo dos sintomas para chegar aos quadros clínicos; e (4) uma terapêutica específica: o tratamento moral. Pinel congregou a legenda de cientista dedicado à alienação mental e seu tratamento, à imagem de filantropo, empenhado em humanizar o trato dos doentes mentais. Defensor da ciência empírica, Pinel defendia a adoção da 
atitude do cientista natural diante da alienação mental. Os sintomas psicopatológicos eram as manifestações que deviam ser descritas, investigadas e classificadas. Na prática, o que ocorreu foi a incorporação de um discurso científico empírico a uma concepção valorativa de base moral, que Ihe dava sustentação. Longe de representar uma contradição, esta assimilação tornou possível a constituição de um novo discurso: o alienismo. Nele, a moralidade foi retirada da órbita das concepções religiosas e encampada pelo discurso científico.

Na sua origem, a constituição do alienismo reforçou o sonho de superação da loucura por meio de uma eficiente gestão técnica e científica, coerente com a utopia iluminista. No entanto, este intento fracassou. Mais adiante, ele irá legitimar um gigantesco processo de exclusão social do doente mental, feito em nome do isolamento terapêutico e do uso indiscriminado e exclusivo de recursos manicomiais. O manicômio, instrumento de cura dos despossuídos da razão em sua concepção originária, transformou-se num meio de cronificação, estigmatização e exclusão destes indivíduos que se propôs a resgatar para a sociedade. A persuasão racional proposta no tratamento moral instaurou um tipo de pedagogia moralizante que assinala a desigualdade presente no par alienista-alienado e confirma o caráter autoritário do poder médico. Ao longo do tempo, o mito humanitário de nascimento do alienismos e torna uma justificativa para o modelo cada vez mais despótico estabelecido pelo saber psiquiátrico. Este confronto irá marcar a história da psiquiatria ao longo do século XX.

\section{Referências}

Beauchesne, H. (1989). História da psicopatologia. São Paulo: Martins Fontes.

Bercherie, P. (1989). Os Fundamentos da clínica: História e estrutura do saber psiquiátrico. Rio de Janeiro: Jorge Zahar.

Castel, R. (1991). A Ordem Psiquiátrica: A Idade de Ouro do Alienismo. Rio de Janeiro: Graal.

Dowbiggin, I. (1991). Inheriting Madness: Professionalization and psychiatric knowledge in nineteenth-century France. Berkeley: University of California Press.

Foucault, M. (1989). História da Loucura na Idade Clássica. São Paulo: Perspectiva.

Goldstein, J. (1987). Console and classify: The French Psychiatric Profession in the Nineteenth Century. New York: Cambridge University Press. 
Oda, A., \& Dalgalarrondo, P. (2007). Apresentação em Pinel, P. Tratado Médico Sobre A Alienação Mental Ou a Mania. Porto Alegre: Editora da UFRGS.

Pessotti, I. (1996). O Século dos manicômios. São Paulo: Editora 34.

Pinel, P. (2007). Tratado Médico-Filosófico sobre a Alienação Mental ou a Mania (J. A. Galli, Trad., A. M. G., Rev. Téc.). Porto Alegre: Editora da UFRGS.

Pinel, P. (1809). Traité médico-philosophique sur L'aliénation mentale (2a ed.). Paris: Brosson.

Postel, J., \& Quetel, C. (1994). Nouvelle Histoire de la Psychiatrie. Paris: Dunod.

Rosenfeld, A. (1988). O Pensamento Psicológico. São Paulo: Perspectiva.

Serpa Jr., O. (1997). Sobre o Nascimento da Psiquiatria em Cadernos do IPUB N. 3: Por uma assistência psiquiátrica em transformação. Rio de Janeiro: UFRJ.

Swain, G. (1997). Le Sujet de la Folie: Naissance de la Psychiatrie. Paris: Calmann-Lévy.

Swain, G. (1994). Dialogue avec L'insensé: Essais d'Histoire de la Psychiatrie. Paris: Gallimard.

\section{Endereço para correspondência \\ Manoel Olavo Loureiro Teixeira \\ Praça Radial Sul, 87/203, Botafogo, CEP 22260-070, Rio de Janeiro - RJ, Brasil \\ Endereço eletrônico: manoelolavo@gmail.com}

Recebido em: 22/05/2019

Aceito em: 03/07/2019

\section{Notas}

* Médico psiquiatra; psiquiatra do Instituto de Psiquiatria da Universidade Federal do Rio de Janeiro; pesquisador adjunto do Instituto Nacional de Infectologia da Fundação Oswaldo Cruz. Doutor em Psiquiatria e Saúde Mental pelo Instituto de Psiquiatria da Universidade Federal do Rio de Janeiro.

Este artigo de revista Estudos e Pesquisas em Psicologia é licenciado sob uma Licença Creative Commons Atribuição-Não Comercial 3.0 Não Adaptada. 